\title{
The letter-frequency effect and the generality of familiarity effects on perception
}

\author{
IRA B. APPELMAN and MARK S. MAYZNER \\ Loyola University of Chicago, Chicago, Illinois
}

\begin{abstract}
A widely accepted perceptual principle is that familiar patterns are easier to recognize than are less familiar patterns. Previous letter-recognition studies are examined to determine whether more frequent letters in English are easier to recognize than less frequent letters (the letterfrequency effect). Most studies required subjects to identify single letters, while some measured reaction time to compare two letters or name or classify a letter. The results, based on over 800,000 observations from 58 studies that span nearly 100 years, showed that: (1) there is no letter-frequency effect in recognition studies in which subjects simply report letters, and (2) there is a letter-frequency effect in reaction time studies. The presence of a letter-frequency effect for reaction time studies is interpreted as demonstrating an effect of familiarity on a comparison stage and perhaps a response stage, but not on input coding. The absence of a letter-frequency effect for single-letter recognition studies is interpreted as limiting the generality of the effect of familiarity on perception and as limiting the generality of models that correctly predict frequency effects for words. Alternative explanations for the absence of a letter-frequency effect are discussed.
\end{abstract}

A widely accepted perceptual principle is that familiar patterns are easier to recognize than less familiar patterns. A common example is the word-frequency effect: words that occur more frequently in the English language are easier to recognize than are words that occur less frequently (Broadbent, 1967; Krueger, 1975). Words are particularly convenient stimuli because their familiarity can be quantitatively determined as their frequency of occurrence in the language.

The word-frequency effect provides consistently replicated, strong quantitative support based on over three decades of research that familiarity facilitates recognition. However, there is another set of stimuli that is often studied and whose familiarity is as easily quantified as words. Those stimuli are the set of 26 letters. If the principle that familiar patterns are easier to recognize than less familiar patterns is truly general, then letters that occur more frequently in English should be easier to recognize than letters that occur less frequently (the letter-frequency effect).

Letter-recognition studies have been reported often over the past 100 years, dating back at least to a study by Sanford (1887). Since data collection has been quite extensive and a great variety of methods have been used, the available results should be capable of providing a definitive answer on the relationship between letter frequency and letter recogniz-

This research was supported by NSF Grant DAR 7923477. Requests for reprints should be sent to either author at: Department of Psychology, Loyola University of Chicago, 6525 North Sheridan Road, Chicago, Illinois 60626. ability. The present study reports a reanalysis of over 800,000 observations from 58 studies conducted over the past 100 years. For each study, the letters are ordered from most often recognized to least often recognized. They are then correlated with the letters ordered from most frequent to least frequent based on available frequency norms.

The paper is organized into three sections. First, a comparison is made between letter-frequency norms we could find that were compiled over the past 100 years. It would be more convenient to correlate letter recognizability in each study with the same norms of letter frequency. This procedure is justified only if letter frequency has remained relatively stable. The second section presents correlations between letter recognizability and letter frequency separately for each study and is organized by the similarity of methods employed. Finally, the implications of the letterfrequency effect for familiarity effects in general are discussed.

\section{STABILITY OF LETTER-FREQUENCY NORMS}

It is desirable to compare the letter-recognition study results with the same letter-frequency norms. That comparison is simplest and does not involve a decision of which letter-frequency norms should be compared with the results of which study. Furthermore, any discovered differences in the relationship between letter frequency and letter recognizability could justifiably be attributed to differences in studies rather than to differences in the accuracies of various norms. The assumption in comparing the results 
of studies reported during a 100-year period to the same norms is that letter frequency has remained fairly stable during that period.

In order to assess the stability of letter frequency in the language, we identified as many letter-frequency norms as possible from the past century. The final sample includes 13 frequency counts that date back 50 years. The counts vary in qualities other than age. The more recent frequency counts tend to be based on a larger sample of written text. The Kučera and Francis (1967) text sample included 4.5 million letters. The individual letter-frequency counts were compiled from that sample by Solso and King (1976). The Mayzner and Tresselt (1965) letter counts were based on a sample of 87,000 letters. The Baddeley, Conrad, and Thomson (1960) norms were based on a sample of 76,000 letters. In contrast, the Gaines (1939) norms are based on a sample of 10,000 letters. The Pratt (1939) norms are based on a sample of 4,500 letters. Tinker (1928) reports only the order of letter frequencies and not the size of the frequency count sample.

For each letter-frequency count, the letters were ranked from most to least frequent. The rankings for each count were correlated with the rankings for all other counts. The results are presented in Table 1 . The most striking result is that the correlations between letter-frequency norms are uniformly large and positive. Apparently neither the date of the count nor sample size made much difference. The smallest correlation (.861) is between the Thorndike-Lorge count and Tinker's count for uppercase letters. The largest correlation (.998) is between Underwood's count and Lysing's count. Since the Kučera and Francis count is based upon the largest sample of letters, and since the correlation between that count and the other counts is uniformly high, we preferred to use the Kučera and Francis count to determine the relationship between letter frequency and letter recognizability in the next section.

The main concern of comparing the frequency counts was stability with time. There is no apparent trend in the correlations between the Kucera and Francis and other counts as a function of the dates of the other counts. The correlation between the 1967 Kučera and Francis count and the next most recent 1965 Mayzner and Tresselt count was .960 . The correlation between the Kucera and Francis count and the oldest 1928 Tinker count of lowercase letters was an equal .961. The average correlation between the Kučera and Francis count and the five most recent counts was .985 . The average correlation between the Kučera and Francis count and the five oldest counts (excluding Tinker's uppercase count) was the same, at $\mathbf{9 8 6}$.

Another important issue concerns the differences in frequency between upper- and lowercase letters. All of the counts except one (Tinker, 1928) are based on text that includes mainly lowercase letters. Most of the letter-recognition studies we will consider used uppercase letters. Therefore, if we are going to use the Kučera and Francis norms, we would like to know that the upper-and lowercase letters do not differ much in frequency. It can be seen in Table 1 that in each case Tinker's uppercase count has a slightly smaller correlation with the other counts than Tinker's lowercase count. This is to be expected if upper- and lowercase counts are not perfectly correlated. Nevertheless, the correlation between Tinker's uppercase and lowercase counts is .929. In using the Kučera and Francis norms with uppercase letter-recognition studies, we are assuming, based on Tinker's data, that the order of letter frequency is quite similar for upper- and lowercase letters.

Table 1

Rank-Order Correlation Coefficients Between Different Letter Frequency Counts

\begin{tabular}{|c|c|c|c|c|c|c|c|c|c|c|c|c|}
\hline \multirow{2}{*}{$\begin{array}{c}\text { Frequency } \\
\text { Count }\end{array}$} & \multicolumn{12}{|c|}{ Frequency Count } \\
\hline & 2 & 3 & $4^{*}$ & $5 *$ & 6 & $7^{*}$ & 8 & 9 & 10 & $11 \dagger$ & 12 & 13 \\
\hline $\begin{array}{l}1 \\
2 \\
3 \\
4^{*} \\
5^{*} \\
6 \\
7^{*} \\
8 \\
9 \\
10 \\
11^{\dagger} \dagger \\
12\end{array}$ & .960 & $\begin{array}{l}.997 \\
.960\end{array}$ & $\begin{array}{l}.994 \\
.972 \\
.991\end{array}$ & $\begin{array}{l}.984 \\
.969 \\
.986 \\
.987\end{array}$ & $\begin{array}{l}.989 \\
.971 \\
.988 \\
.993 \\
.977\end{array}$ & $\begin{array}{l}.966 \\
.908 \\
.962 \\
.958 \\
.942 \\
.960\end{array}$ & $\begin{array}{l}.988 \\
.952 \\
.987 \\
.987 \\
.972 \\
.983 \\
.955\end{array}$ & $\begin{array}{l}.991 \\
.952 \\
.992 \\
.980 \\
.981 \\
.977 \\
.963 \\
.978\end{array}$ & $\begin{array}{l}.995 \\
.973 \\
.995 \\
.998 \\
.990 \\
.992 \\
.956 \\
.987 \\
.984\end{array}$ & $\begin{array}{l}.993 \\
.951 \\
.992 \\
.986 \\
.980 \\
.982 \\
.956 \\
.993 \\
.992 \\
.989\end{array}$ & $\begin{array}{l}.910 \\
.912 \\
.919 \\
.900 \\
.888 \\
.919 \\
.861 \\
.906 \\
.906 \\
.910 \\
.905\end{array}$ & $\begin{array}{l}.961 \\
.956 \\
.965 \\
.961 \\
.961 \\
.964 \\
.905 \\
.968 \\
.960 \\
.963 \\
.967 \\
.929\end{array}$ \\
\hline
\end{tabular}

Note-Frequency counts: (1) KuČera \& Francis (1967), (2) Mayzner \& Tresselt (1965), (3) Baddeley et al. (1960), (4) Underwood (1960), (5) Encyclopedia Americana (1956), (6) Attneave (1953), (7) Thorndike \& Lorge (1944), (8) Pratt (1939), (9) Gaines (1939), (10) Lysing (1936), (11) O'Haver (1936), (12) Tinker (1928) uppercase, (13) Tinker (1928) lowercase.

* Data from Underwood \& Schulz (1960). TData from Gaines (1939). 


\section{LETTER FREQUENCY AND LETTER RECOGNIZABILITY}

The relationship between letter frequency and letter recognizability was determined for each letterrecognition study by ranking the letters from most easily recognized to least easily recognized and correlating those ranks with letters ranked from most frequent to least frequent based on the Kučera and Francis norms. The correlations obtained from this procedure are grouped into three tables, Tables 2 through 4. The tables and other results presented in this section represent over 800,000 observations from 58 studies. In some studies, the authors presented individual subject data or more than one set of data from the same condition, instead of averaged data. Rather than presenting correlations between letter frequency and recognizability for different sets of data representing essentially the same conditions of a study, we reduced the already large number of results by averaging across subjects or different data from the same condition. In each case, we checked the individual data first before averaging. In no case was the average markedly different from the unaveraged data. That is, we did not average data showing a moderate positive relationship between letter frequency and letter recognizability with data showing a moderate negative relationship to get an average with no relationship. The exception to this checking procedure was the treatment of government laboratory reports (e.g., Shurtleff, 1970a, 1970b). These studies are often based on conditions that produce very few errors. Therefore, the presented results of a study were often combined before the relationship between letter frequency and recognizability was tested.

Table 2 presents the correlations between letter frequency and letter recognizability for letterrecognition studies that used uppercase letters. The studies are presented in chronological order. There were two methods of stimulus presentation designed to insure that subjects would make some letterrecognition errors. One method was to present the letter for a short duration, sometimes followed by a visual pattern mask. The other method was to present the letter for a longer duration but at a distance, in the periphery, or defocused so that it was difficult to see. The method of presentation is indicated in the table. Most studies employed the full alphabet of 26 letters, but if fewer than 26 were used, that is indicated in the table. The government laboratory reports often included the 10 digits along with the letters. Most of the studies involve visual presentation of letters. Appended to the table are a few studies that employed tactile presentation of uppercase letters to blind and sighted subjects.

Is there a positive relationship between letter fre- quency and letter recognizability for uppercase letters? The answer appears to be no. The rank-order correlation coefficients range from -.426 to .230 . In order to reach statistical significance for a study based on 26 letters, the correlation must be greater than .391 or less than -.391 . Of 43 conditions from the 38 studies listed in Table 2 , absolutely none of the positive correlations reached statistical significance, nor were any particularly close. The only statistically significant correlation was negative for Tinker's study.

It is of some interest to be able to combine the results reported in Table 2 into a single test of the relationship between letter frequency and recognizability for uppercase letters. The individual significance tests of the rank-order correlation coefficient, rho, are based on the result that a standard ratio of rho is t-distributed when the number of paired scores is 10 or larger (Siegel, 1956, p. 212). Assuming that the values of rho in Table 2 are based on independent experiments, the individual $t$ statistics can be combined into a ratio that is normally distributed if each $t$ statistic has at least 10 degrees of freedom (Winer, 1971, p. 50). This overall test for the results in Table 2 also fails to indicate a relationship between letter frequency and recognizability $(\mathrm{z} \doteq 1.09, \mathrm{p}>.25)$. So the evidence is quite clear that there is not a positive relationship between letter frequency and letter recognizability for studies presenting uppercase letters.

Table 3 presents the correlations between letter frequency and letter recognizability from letterrecognition studies that used lowercase letters. The studies are again presented in chronological order, with method of stimulus presentation indicated in the table. We have included two studies (Popp, 1964; Smith, 1928) in which preschoolers with minimal letter experience matched letters using a forced-choice procedure. There is a striking difference between the results for lowercase letters and uppercase letters. Most of the lowercase studies show a negative correlation between letter frequency and letter recognizability. Of the 14 conditions from 12 studies, 5 reached statistical significance $\left(r_{s}<-.391\right)$. Burtt and Basch (1923) used only 18 letters, and the correlation of -.472 falls just short of the critical value of -.474 .

A test of the combined outcomes of the conditions listed in Table 3 indicated a negative relationship between letter frequency and recognizability $(z=-4.76$, $\mathrm{p}<.001)$. The finding of a negative relationship between letter frequency and recognizability is probably conservative since two of the three positive rhos in Table 3 are based on preschoolers with minimal letter experience. Even if there is a relationship for adults, preschoolers might not show it. The combined test assumes that the individual outcomes are based on independent experiments. The reader may 
Table 2

Rank-Order Correlation Coefficients Between Letter Frequency and Letter Recognizability for Uppercase Letter Recognition Studies

\begin{tabular}{|c|c|c|}
\hline Study & Method & Rho \\
\hline Roethlein (1912) & Distance & .011 \\
\hline Ewing (1922) & Gothic, 18 letters & .226 \\
\hline Ewing (1922) & Block, 18 letters & .014 \\
\hline Hartridge \& Owen (1922) & Distance, 21 letters & .071 \\
\hline Burtt \& Basch (1923) & Focus, 18 letters & -.214 \\
\hline Banister et al. $(1926,1927)^{*}$ & Distance & .230 \\
\hline Banister et al. $(1926,1927)^{*}$ & Brief exposure & .133 \\
\hline Banister (1927) & Brief exposure & .220 \\
\hline Tinker (1928) & Brief exposure & $-.426^{* *}$ \\
\hline Reinwald (1955) & Distance & .242 \\
\hline Harris et al. (1956) & Reduced illumination & .163 \\
\hline Howell \& Kraft (1959) & Size, focus, contrast & .223 \\
\hline Hodge (1962) & Distance & .176 \\
\hline Pew \& Gardner (1965) $\dagger$ & Masking & .180 \\
\hline Kinney et al. (1966) & Brief exposure & -.269 \\
\hline Kinney \& Showman (1966) & Brief exposure & .010 \\
\hline Showman (1966) & Brief exposure & -.012 \\
\hline Shurtleff et al. (1966) & Distance & .081 \\
\hline Bell (1967a) & Brief exposure, 24 letters & .003 \\
\hline Bell (1967b) & Focus, 24 letters & .125 \\
\hline Uttal \& Smith (1968) & Brief exposure, 24 letters & .186 \\
\hline Fisher et al. (1969) & Brief exposure & .146 \\
\hline Uttal (1969) & Masking, 24 letters & -.058 \\
\hline Shurtleff (1970a) & Distance & .140 \\
\hline Shurtleff $(1970 \mathrm{~b})$ & Distance & .164 \\
\hline Townsend (1971a) & Brief exposure & -.028 \\
\hline Townsend (1971a) & Masking & .056 \\
\hline Townsend (1971b) & Brief exposure & -.256 \\
\hline Rogers (1973) & Masking, 25 letters & -.019 \\
\hline Birns (1974) & Masking, 24 letters & -.097 \\
\hline Apkarian-Stielau \& Loomis (1975) & Focus & .052 \\
\hline Goble (1975) & Masking & -.048 \\
\hline Mayzner (1975) & Masking, 25 letters & -.004 \\
\hline Loomis \& Apkarian-Stielau (1976) & Focus & -.162 \\
\hline Maddox et al. (1977)†† & Masking & .071 \\
\hline Snyder \& Maddox (1978) & Masking & -.013 \\
\hline Gilmore et al. (1979) & Brief exposure & -.061 \\
\hline Appelman \& Mayzner (Note 1) & Masking & -.080 \\
\hline Loomis (1974) & Tactile, blind and sighted & .165 \\
\hline Apkarian-Stielau \& Loomis (1975) & Tactile & .230 \\
\hline Loomis \& Apkarian-Stielau (1976) & Tactile & -.035 \\
\hline Craig (1979) & Tactile & .035 \\
\hline Kikuchi et al. (1979) & Tactile, blind subjects & -.004 \\
\hline
\end{tabular}

*Data from Tinker (1928). * ** <.05. TData from Fisher et al. (1969). † Data from Snyder \& Maddox (1978).

conclude that certain outcomes, such as those from the same study, are not independent. If so, the table contains all the information necessary to recalculate the statistic with conditions eliminated, although we do not believe eliminating one or two conditions will make much difference.

The relationship between letter frequency and letter recognizability for lowercase letters appears to be negative, or at least it is clear that the relationship is not positive. The result will be important later when we discuss the effect of familiarity on recognition. So far, all the studies reviewed have been accuracy studies that require subjects to identify letters and measure the proportion of errors. The major alternative to this procedure is the reaction-time study that requires subjects to respond to letters and measures the time it takes for them to respond. Table 4 presents the correlations between letter frequency and the speed of correct responses from the reaction time studies. Most of the studies involve same-different tasks in which two letters are presented and the subject responds as to whether they are the same or different. In theory, the same-different task does not require letter recognition, since the two patterns can be compared for sameness without first being identified as letters or as particular letters. The correlations reported in Table 4 for same-different tasks are for correct responses to pairs of letters that are the same. Cosky (1976) required subjects to discriminate between letters and nonletters or to name letters. 
Table 3

Rank-Order Correlation Coefficients Between Letter Frequency and Letter Recognizability for Lowercase Letter Recognition Studies

\begin{tabular}{llrr}
\hline \multicolumn{1}{c}{ Study } & & \multicolumn{2}{c}{ Letters } \\
\cline { 2 - 4 } Sanford (1887) & \multicolumn{1}{c}{ Method } & All & Short \\
Sanford (1887) & Distance, Table 1 & $-.461^{*}$ & -.300 \\
Dockeray (1910) & Brief exposure & $-.434^{*}$ & -.231 \\
Roethlein (1912) & Peripheral vision & $-.436^{*}$ & -.323 \\
Burtt \& Basch (1923) & Distance & -.292 & -.258 \\
Crosland \& Johnson (1928) & Focus, 18 letters & -.472 & -.479 \\
Smith (1928) & Brief exposure, correct position & .167 & .187 \\
Tinker (1928) & Matching & .162 & .022 \\
Hodge (1962) & Brief exposure & $-.522^{*}$ & -.645 \\
Popp (1964) & Distance & $-.417^{*}$ & -.544 \\
Bouma (1971) $\dagger$ & Matching & -.219 & .187 \\
Bouma (1971) $\dagger$ & Distance & -.167 & .151 \\
Engel et al. (1973) & Peripheral vision & -.238 & .206 \\
Geyer (1977) & Brief exposure & -.326 & .121 \\
\hline
\end{tabular}

$* p<.05 . \quad$ tBased on letter frequencies in Dutch from Bouma's Figure 7.

Table 4

Rank-Order Correlation Coefficients Between Letter Frequency and Speed of Correct Responses for Reaction Time Studies

\begin{tabular}{lll}
\hline \multicolumn{1}{c}{ Study } & \multicolumn{1}{c}{ Method } & Rho \\
\hline Clement \& Carpenter (1970) & Same-different, 17 letters & .452 \\
Fox (1975) & Same-different, 20 letters & .191 \\
Cosky (1976) & Letter/nonletter discrimination & $.415^{*}$ \\
Cosky (1976) & Letter naming & $.565^{*}$ \\
Egeth et al. (1976) & Same-different, 14 letters & .359 \\
Podgorny \& Garner (1979) & Same-different & $.532^{*}$ \\
\hline
\end{tabular}

${ }^{*} p<.05$.

There is relatively little reaction-time data available, and that is why Table 4 is based on only five studies. Though there are a large number of reactiontime studies, the results are rarely provided for each letter separately. The most striking result for reactiontime studies is that they are the only set of studies to produce statistically significant positive correlations. In each case, more frequent letters in the language are responded to more quickly. Three of the six conditions yielded statistically significant results $\left(r_{s}\right\rangle$ .391). The Clement and Carpenter (1970) study was based on only 17 of the 26 letters, and that is why the correlation of .452 fails to reach statistical significance. The combined test of all six conditions indicated a statistically significant positive relationship between letter frequency and recognizability $(z=4.92$, $\mathrm{p}<.001$ ). If the two conditions from Cosky's study are excluded and the same-different experiments are considered alone, the positive relationship is still statistically significant $(z=3.37, p<.001)$.

In summary, the correlation between letter frequency and recognizability is negative for accuracy studies using lowercase letters, positive for reactiontime studies using uppercase letters, and neither positive nor negative for accuracy studies using uppercase letters. This implies, at least for accuracy studies, that familiarity (letter frequency) does not aid recognition. This result is in sharp contrast to the wordfrequency effect found in both accuracy and reaction time studies. In the next section, the difference between accuracy and reaction-time studies will be discussed with respect to the letter-frequency effect and what that implies about the locus of the frequency effect. But, before discussing the implications of the letter-frequency effect, we first discuss possible effects that could mask a letter-frequency effect.

\section{Possible Effects That Could Mask \\ a Letter-Frequency Effect}

Since we cannot manipulate the frequency of letters in the language, we must be satisfied with correlating letter frequency with letter recognizability if we wish to study letters. An alternative approach would be to generate a new set of symbols and vary the frequency with which subjects see them over an extended period of time. Nevertheless, letters like words are a legitimate set of naturalistic stimuli whose study should be capable of providing quantitative answers to questions about the effect of familiarity on perception. It is possible that other properties of letters are interfering with our detecting a frequency effect, and we consider them now. 
One possibility is that there is a limit to how much frequency can aid recognition and letters are so frequent that there is a ceiling effect of frequency on recognizability. Let us compare letters with words using the Kučera and Francis sample of one million words. The most frequent word ("the") occurs 69,971 times, and the least frequent words occur once. The most frequent letter (" $e$ ") occurs 577,583 times, and the least frequent letter (" $z$ ") occurs 4,316 times. Though there is a large range in frequency of occurrence for letters, even the least frequent letter occurs more often than all but a few of the words. Of the 50,406 words in the sample, only 27 occurred more frequently than the least frequent letter. Hall (1954) found that the word-frequency effect was greater at the lower end of the scale (words occurring 1 vs. 10 times per million) than at the upper end of the scale, at which he found no frequency effect (words occurring 30 vs. 50-100 times per million). The only argument we can offer against a ceiling effect is that there is a letter-frequency effect for reaction-time studies. Although it is possible that letters are so frequent that frequency does not affect letter recognition, the reaction time results show that at least some types of single-letter processing are affected by letter frequency.

Another possibility is that certain letters, because of their visual properties, are easier to recognize than other letters. Sometimes this issue is raised with respect to the complexity of a pattern influencing how easy it is to recognize (Henle, 1942). If, by chance, high-frequency letters have visual properties that make them more difficult to recognize, then a letterfrequency effect could be masked. Bouma (1971), in a lowercase letter-recognition study, correlated letter frequency in Dutch with recognizability for two conditions. He found slight negative Pearson correlations of -.28 and -.16 , which agree with our results. Bouma noticed that the four descenders $(g, j, p$, and $y$ ) are relatively low-frequency letters and yet are relatively easy to recognize. It could be that the visual property of descending or ascending makes lowercase letters easier to recognize. He calculated correlations for the short letters only (a, c, e, m, n, o, r, s, u, v, w, $x, z)$ and found that the negative Pearson correlations were reduced to -.12 and 0.0 . Thus, the visual property of ascending and descending contributed to a negative relationship between frequency and recognizability. This would tend to mask a letter-frequency effect, although Bouma did not find a letter-frequency effect for the short letters alone.

Since we also found a negative correlation between frequency and recognizability for lowercase letters, we recalculated correlations for the short letters only. The results are shown in the last column of Table 3 along with rank-order correlations for Bouma's two conditions. In 8 of the 12 new conditions, the correlations are more positive for the short letters than for all letters. In agreement with Bouma (1971), the correlations generally become more positive if the ascenders and descenders are eliminated, but most of the correlations for the studies in Table 3 are more negative to begin with than Bouma's for all letters and they generally remain negative for the short letters alone. While the property of ascending and descending has a slight tendency to mask a letterfrequency effect for lowercase letters, this does not apply to uppercase letters. At this point, we cannot identify a visual property that could mask the letterfrequency effect for uppercase letters, but that possibility cannot be completely ruled out.

A final possibility is that set properties of the alphabet mask a letter-frequency effect. It is generally believed that one reason letters are difficult to recognize is that they are visually confused with other letters in the set (for example, E and F, C and G, O and Q). It is possible that, by chance, high-frequency letters are more visually similar to the rest of the letters in the alphabet than are low-frequency letters, and that that is masking a letter-frequency effect. In order to test this possibility, we reanalyzed the data from seven studies that presented considerably fewer than 26 letters. None of the studies originally addressed the issue of letter frequency, and all presented uppercase letters. If the set properties of letters are masking a letter-frequency effect, then rearranging the letters into different sets should, at least in some cases, allow the letter-frequency effect to show through.

Table 5 presents the rank-order correlations between recognizability and frequency for only the letters in each particular set. In each case, the actual letters used in a condition are listed. A particularly relevant study is that of Birns (1974), which presented 24 letters (minus $O$ and $Q$ ) arranged in sets of 12,8 , and 6 . For all the studies, the correlations range from -.657 to +.314 . In no case are the correlations statistically significant. Rudie (1974) specifically constructed letter sets so that one (the first in Table 5) included letters that were easily confused and the other included letters that were not easily confused. In neither condition was a letter-frequency effect evident. Though we cannot entirely eliminate the possibility, we do not have evidence of either a ceiling effect or that single-letter properties or set properties are masking a letter-frequency effect.

\section{DISCUSSION}

The main results from our reanalysis of the data from 58 letter-recognition studies are as follows. For accuracy studies, there is no evidence of a familiarity effect. More frequent letters are not easier to recognize. For reaction-time studies, there is evidence of a familiarity effect. The difference between accuracy and reaction-time results is unusual, since they nor- 
Table 5

Rank-Order Correlation Coefficients Between Letter Frequency and Letter Recognizability for Letter Recognition Studies Using Small Sets

\begin{tabular}{llr}
\hline \multicolumn{1}{c}{ Study } & \multicolumn{1}{c}{ Letters } & \multicolumn{1}{c}{ Rho } \\
\hline Rumelhart (Note 2) FS & ABCDEF & -.657 \\
Rumelhart (Note 2) GM & ABCDEF & -.086 \\
Rumelhart (Note 2) RS & ABCDEF & -.371 \\
Levine (1973) & ABCFINPSTY & .079 \\
Burns (1973) & CDGLOTWX & -.395 \\
Rudie (1974) & ITXYAHMN & -.476 \\
Rudie (1974) & AILVDKWZ & -.623 \\
Birns (1974) & ACDEFJSTVWYZ & .018 \\
Birns (1974) & BGHIKLMNPRUX & -.168 \\
Birns (1974) & DEGJLRSW & -.048 \\
Birns (1974) & BCKNPTUV & -.262 \\
Birns (1974) & AFHIMXYZ & -.220 \\
Birns (1974) & CDTVYZ & .143 \\
Birns (1974) & BHKNRU & -.522 \\
Birns (1974) & AEFJSW & .314 \\
Birns (1974) & GILMPX & -.029 \\
Mayzner \& Habinek (Note 3) & CFHLNTXZ & .204 \\
Fischer (1979) & ABEFIKLRTX & .006 \\
\hline
\end{tabular}

mally provide similar results (Smith \& Spoehr, 1974).

A standard conceptualization of the role of familiarity in letter-recognition studies is as follows. If the letters must be named or identified, then familiarity has an effect. If the letters need only be matched in a reaction-time task, then familiarity has no effect, since the matching can be based on a physical representation without first naming or identifying the letters (Posner, 1969, pp. 49-53).

Posner and Mitchell (1967) reported that subjects could visually match unfamiliar Gibson forms as fast as they could letters, thus demonstrating the absence of a familiarity effect for the matching task. Most of the results for reaction-time matching tasks have not, however, supported the original Posner and Mitchell findings. Matching times that were faster for pairs of normal than for pairs of rotated letters have been found by Ambler and Proctor (1976), Egeth and Blecker (1971), Friden (1973), Hock, Gordon, and Marcus (1974), and Krueger (1973). Young and Hodge (1980) found no difference between matching times for pairs of normal and rotated letters, but both were matched faster than nonsense forms. Ambler and Proctor (1976) found that Japanese subjects responded faster to Japanese letters than to English letters and that American subjects responded faster to English letters than to Japanese letters. The bulk of the evidence has demonstrated a familiarity effect for the letter-matching task. Our finding of a letter-frequency effect for reaction-time studies lends further support to the demonstration of a familiarity effect in a task that presumably does not require subjects to identify the two patterns being matched.

Demonstrations of a familiarity effect where stim- uli must be named or identified have not, for the most part, involved single letters. The word-frequency effect and the word-superiority effect-that it is easier to recognize letters in words than letters in nonwords-have provided ample evidence of the advantage of past experience in identifying multiplesymbol displays. The effect of familiarity has not, however, been convincingly demonstrated at the level of letters. Henle's (1942) study, which compared recognition of letters and digits with reversed letters and digits, is often cited as a letter-recognition study that demonstrates a familiarity effect. However, the condition in that study that is comparable to the studies we have considered, in which subjects were most likely aware that they would be seeing letters and digits or reversals, produced no significant familiarity effect. The familiarity effect occurred only in the conditions in which letters and reversed letters were mixed into a series that consisted mainly of nonsense forms. The subjects were not told that they would be seeing letters and digits and their reversals. The problem created by this procedure lies in the scoring of the accuracy of a response. Henle reports that a "reproduction of a letter-form was scored as positive if it was made as people print the letter or reversed letter in question regardless of whether the letter was actually named or not" (p. 6). Not enough information is provided to determine whether the familiarity effect was real or a product of the scoring procedure.

The only other study we know of that demonstrates a familiarity effect for single letters is that of Robinson, Brown, and Hayes (1964). This study has been criticized as providing too little information about the procedure to make evaluation of the results possible (Egeth \& Blecker, 1971). In one condition, subjects identified one of five letters $(B, E, G, N$, or Z). Robinson et al. report that identification thresholds were affected by letter frequency. However, what they apparently tested was whether there was a difference between thresholds for letters. They do not report a test of trend to show that more frequent letters are easier to recognize. Based on their Figure 3, the main result was that it was more difficult to recognize the letter $Z$ than the other letters. Since $Z$ is a low-frequency letter, it may appear that lowfrequency letters are difficult to recognize. However, the facilitating effect of frequency on recognition does not hold for the other four letters taken alone. More generally, before concluding that letter-frequency affects recognition, we must know why these particular five letters were chosen for the study. The results of that study showed that $\mathrm{Z}$ was by far the most difficult letter to recognize, which is unusual. In the conditions reported for uppercase letters in our Table $2, \mathrm{Z}$ was identified more often than at least one of the other four letters (B, E, G, and N) $88 \%$ of the time. The poor performance for $\mathrm{Z}$ in the Robinson 
et al. study could be a result of the choice of the other four letters.

It is usually imprudent to conclude that an effect does not exist based on failure to find it. The exception is when experiment after experiment fails to find it. Our reanalysis of the data from accuracy letter-recognition experimenis has failed to find a single positive correlation between letter frequency and letter recognizability. Though the common belief is that when stimuli must be identified familiarity will have an effect, there is no strong evidence to argue for this at the letter level. We will now consider the implications of a familiarity effect for reactiontime studies and the lack of a familiarity effect in accuracy studies for the possible cause or causes of the familiarity effect.

Krueger (1975) has discussed a variety of singleand multiple-letter studies with respect to the locus of the familiarity effect in the information processing sequence (e.g., input coding, storage, comparison, response). Here we restrict ourselves to single-letter studies, which is usually considered to rule out storage as a possible locus of the familiarity effect. The main evidence that we provide is that familiarity affects reaction-time studies but not letter-recognition studies that involve accuracy alone. The failure to find a familiarity effect in accuracy studies appears to rule out input coding as a locus of the familiarity effect.

It appears to us that the conclusion most consistent with our results and with other results in the literature is that familiarity affects the comparison process. An obvious difference between accuracy studies and the matching studies is that the matching studies require subjects to compare presented stimuli while the accuracy studies do not. Almost all of the evidence for a familiarity effect for single letters involves the matching of letters, rotated letters, or nonsense forms. Furthermore, using additive factors logic, Ambler and Proctor (1976) found that, in a memory-search task, the slower response times of subjects to Japanese letters than to English letters were attributable to the comparison and not to the encoding stage.

Though it seems that attributing the familiarity effect to the comparison process is the most consistent interpretation of our results, it does not explain everything. In particular, we find a positive correlation between letter frequency and reaction time for Cosky's (1976) two conditions. Cosky used a letter/ nonletter discrimination task and a letter naming task, neither of which involve comparisons. It is possible that familiarity affects the speed of a response stage. Certainly, the main difference between reaction time and accuracy studies is that reaction-time studies monitor the speed of responding. There is evidence that subjects have a bias for guessing more frequent letters. Mayzner, Tresselt, Adler, and Schoenberg (1964) had subjects simply generate letters at random without stimulus presentation. The correlation between letter frequency and the number of letters generated for various conditions ranged from .71 to .83. Furthermore, in a lowercase letterrecognition study, Bouma (1971) reported correlations of up to .6 between letter frequency and the number of times a letter was given as an incorrect response. Since subjects appear to be biased to output more frequent letters, that could affect the speed of a response stage. However, a bias to respond with more frequent letters would not necessarily affect accuracy study results, since the probability of correctly guessing a letter is quite small.

It appears to us that the presence of a letterfrequency effect for reaction-time studies and its absence for accuracy studies indicates that familiarity affects a comparison or response stage, or both, but not input coding. If familiarity affects input coding, then that should be reflected in the correlation between letter frequency and letter recognizability. An alternative interpretation of the difference between reaction-time and accuracy studies is that reaction time is more sensitive than accuracy as a measure of familiarity effects. It is usually awkward to conclude that an effect does not exist when a single experiment does not find it. It is always possible that the experiment was not sensitive enough, though we have shown that 43 conditions from 38 accuracy studies have failed to find a statistically significant positive relationship between letter frequency and recognizability. It is possible that accuracy itself is an insensitive measure, although accuracy has not proved to be insensitive in detecting word-frequency effects.

We began this report by posing the general question of the effect of familiarity on perception. Though the clear word-frequency effect appeared to support the generality of familiarity effects, the absence of a letter-frequency effect limits that generality. Recent discussions of the word-frequency effect have considered the properties of two models (Broadbent, 1967; Morton, 1969). The sophisticated guessing model claims that partial information from the visual display constrains possible responses, and the subjects guess with a bias toward more probable stimuli. For words, it is often assumed that the partial information is in the form of letters. The criterion-bias model claims that subjects require less information from the display in order to output more probable stimuli. It has proved difficult to distinguish these models experimentally, and both remain viable as explanations of the word-frequency effect. It is clear from discussions of these models (e.g., Broadbent, 1967; Neisser, 1967) that they are intended to be quite general even though they are being applied to the more easily studied word stimuli. It should, however, 
be understood that the authors have not predicted a letter-frequency effect and have not applied their models to letters. When applied to letters, the sophisticated guessing model claims that partial information in the form of features is obtained from the visual display by subjects, who guess with a bias toward more probable stimuli. The criterion-bias model claims that subjects require fewer features from the display in order to output more probable stimuli. Of course, for single-letter displays both of these models must be rejected. Unlike the case for words, there is no letter-frequency effect in the accuracy study results that the models are designed to explain.

It should be noted that conditions based on a small number of stimuli have failed to show a wordfrequency effect in the past (Morton, 1964; Pierce, 1963). Pierce presented 12 words to each subject. In one condition the subjects were given an alphabetical list of the words, and in another condition they were not given a list. The condition without a list produced a word-frequency effect, but the list condition did not. For letter-recognition studies, the alphabet is necessarily a relatively small set and subjects would not need a list to know what the stimuli were. Pierce explained her results with a sophisticated guessing model. Subjects without the list guess with a bias for more frequent words, creating a word-frequency effect, while subjects with the list do not guess with a bias toward more frequent words. This explanation cannot account for the absence of a letter-frequency effect because, as mentioned previously, the letterfrequency effect is absent even in conditions in which subjects' error responses show a clear bias to respond with more frequent letters (Bouma, 1971).

Although we have presented possible reasons for the absence of a letter-frequency effect, our most striking finding is that not one of $\mathbf{5 3}$ accuracy studies has shown that familiarity reliably aids recognition. The sophisticated guessing and criterion-bias models have been contrasted with a pure guessing model (Broadbent, 1967) that generates more frequent stimuli but does not result in a familiarity effect since the probability of guessing a word correctly is so small. The critical question is whether the process responsible for responding with more frequent stimuli can take advantage of partial information from the display to limit responses. For words, this may be true, but for letters, it appears that feature information is not available to that process, and thus the tendency of subjects to respond with more frequent letters is probably best conceptualized as pure guessing that does not lead to a letter-frequency effect.

\section{RETERENCE NOTES}

1. Appelman, I. B., \& Mayzner, M. S. Unpublished data with a multiple-random-staircase masking procedure, 1981.
2. Rumelhart, D. E. A multicomponent theory of confusion among briefly expased alphabetic characters. CHIP 22 from the Center for Human Information Processing, University of California, San Diego, 1971.

3. Mayzner, M. S., \& Habinek, J. K. Visual information processing of letters and nonletters. Paper presented at the Sixteenth Annual Meeting of the Psychonomic Society, Denver, Colorado, 1975.

\section{REFERENCES}

Ambler, B. A., \& Proctor, J. D. The familiarity effect for singleletter pairs. Journal of Experimental Psychology: Human Perception and Performance, 1976, 2, 222-234.

Apkarian-Stielau, P., \& Loomis, J. M. A comparison of tactile and blurred visual form perception. Perception \& Psychophysics, 1975, 18, 362-368.

Attneave, F. Psychological probability as a function of experienced frequency. Journal of Experimental Psychology, 1953, 46, 81-86.

Baddeley, A. D., Conrad, R., \& Thomson, W. E. Letter structure in the English language. Nature, 1960, 186, 414-416.

Banister, H. Block capital letters as tests of visual acuity. British Journal of Ophthalmology, 1927, 11, 49-61.

Banister, H., Hartridae, H., \& Lythgoe, R. J. The influence of illumination on visual acuity. In Proceedings of the Optical Convention. London: 1926.

Banister, H., Hartridae, H., \& Lythgoe, R. J. The effect of illumination and other factors on the acuity of vision. British Journal of Ophthalmology, 1927, 11, 321-330.

BeLL, G. L. The effect of symbol frequency in legibility testing. Human Factors, 1967, 9, 471-478. (a)

BeLL, G. L. Studies of display symbol legibility: Part XVI. The legibility of teletypewriter symbols on television (ESD-TR-67104). Hanscom Field, Mass: USAF Electronic Systems Division, April 1967. (NTIS No. AD 655 356) (b)

BIRns, M. L. The effect of group size and preparatory set on recognition of alphabetic inputs. Unpublished doctoral dissertation, New York University, 1974.

Bouma, H. Visual recognition of isolated lower-case letters. Vision Research, 1971, 11, 459-474.

Broadbent, D. E. Word-frequency effect and response bias. Psychological Review, 1967, 74, 1-15.

Burng, R. F. Recognition of rotated and reflected alphabetic characters (Doctoral dissertation, New York University, 1973). Dissertation Abstracts International, 1974, 35, 535B. (University Microfilms No. 74-15920)

BurtT, H. E., \& BAsch, C. Legibility of Bodoni, Baskerville Roman, and Cheltenham type faces. Journal of Applied Psychology, 1923, 7, 237-245.

Clement, D. E., \& Carpenter, J. S. Relative discriminability of visually-presented letter pairs using a same-different choicereaction time task. Psychonomic Science, 1970, 20, 363-364.

Cosky, M. J. The role of letter recognition in word recognition. Memory \& Cognition, 1976, 4, 207-214.

Craig, J. C. A confusion matrix for tactually presented letters. Perception \& Psychophysics, 1979, 26, 409-411.

Crosland, H. R., \& Johnson, G. The range of apprehension as affected by inter-letter hair-spacing and by the characteristics of individual letters. Journal of Applied Psychology, 1928, 12, 82-124.

Dockeray, F. C. The span of vision in reading and the legibility of letters. Journal of Educational Psychology, 1910, 1, 123-131.

Egeth, H., \& Blecker, D. Differential effects of familiarity on judgments of sameness and difference. Perception \& Psychophysics, 1971, 9, 321-326.

Eoeth, H., Brownell, H., \& Georprion, L. Testing the role of symmetry in letter matching. Journal of Experimental Psychology: Human Perception and Performance, 1976, 2, $429-434$. Engel, G. R., Dougherty, W. G., \& Jones, G. B. Correlation 
and letter recognition. Canadian Journal of Psychology, 1973, 27, 317-326.

Ewing, A. E. The value of letters and characters as visual tests. In An International Congress of Ophthalmology, Washington, D.C: 1922.

Fischer, H. Visual information processing of degraded alphabetic inputs (Doctoral dissertation, Polytechnic Institute of New York, 1979). Dissertation Abstracts International, 1979, 40, 1398B. (University Microfilms No. 79-20777)

Figher, D. F., Monty, R. A., \& Gluckseerg, S. Visual confusion matrices: Fact or artifact? Journal of Psychology, 1969, 71, 111-125.

Fox, J. The use of structural diagnostics in recognition. Journal of Experimental Psychology: Human Perception and Performance, 1975, 104, 57-67.

Friden, T. P. The effects of familiarity in a perceptual matching task. Perception \& Psychophysics, 1973, 14, 487-492.

GAINES, H. F. Cryptanalysis: A study of ciphers and their solutions. New York: Dover, 1939.

GEYER, L. H. Recognition and confusion of the lowercase alphabet. Perception \& Psychophysics, 1977, 22, 487-490.

Gilmore, G. C., Hersh, H., Caramazza, A., \& Griffin, J. Multidimensional letter similarity derived from recognition errors. Perception \& Psychophysics, 1979, 25, 425-431.

Goble, L. G. Filtered 2-dimensional discrete Fourier and Walsh transform correlation with recognition errors and similarity judgments (Doctoral dissertation, University of Michigan, 1975). Dissertation Abstracts International, 1976, 36, 5334B. (University Microfilms No. 76-09401)

Hall, J. F. Learning as a function of word-frequency. American Journal of Psychology, 1954, 67, 138-140.

Harris, W. P., Green, B. F., Wilson, E. A., \& Liaudansky, L. H. The design of characters for the Charactron (Tech. Rep. 117). Lexington, Mass: Lincoln Laboratory, May 1956. (NTIS No. AD 101 142)

Hartridge, H., \& OWen, H. B. Test types. British Journal of Ophthalmology, 1922, 6, 543-549.

Henle, M. An experimental investigation of past experience as a determinant of visual form perception. Journal of Experimental Psychology, 1942, 30, 1-22.

Hock, H. S., Gohdon, G. P., \& Marcus, N. Individual differences in the detection of embedded figures. Perception \& Psychophysics, 1974, 15, 47-52.

HODGE, D, C. Legibility of a uniform-strokewidth alphabet: 1. Relative legibility of upper and lower case letters. Journal of Engineering Psychology, 1962, 1, 34-46.

Howell, W. C., \& KRAFT, C. L. Size, blur, and contrast as variables affecting the legibility of alpha-numeric symbols on radar-type displays (WADC Tech. Rep. 59-536). Columbus: Laboratory of Aviation Psychology, Ohio State University, September 1959. (NTIS No. AD 232 889)

Kikuchi, T., Yamashita, Y., Sagawa, K., \& Wake, T. An analysis of tactile letter confusions. Penception \& Psychophysics, $1979,26,295-301$.

Kinney, G. C., Marsetta, M., \& Showman, D. J. Studies in display symbol legibility: Part XII. The legibility of alphanumeric symbols for digitalized television (ESD-TR-66-117). Hanscom Filed, Mass: USAF Electronic Systems Division, November 1966. (NTIS No. AD 646 660)

KINNE Y, G., \& Show man, D. Studies of display symbol legibility: Part XIII. Studies of the legibility of alphanumeric symbols in the BUIC symbol (ESD-TR-66-302). Hanscom Field, Mass: USAF Electronic Systems Division, August 1966. (NTIS No. AD 638 664)

KrUEaER, L. E. Effect of letter-pair frequency and orientation on speed of "same".-"different" judgments by children and adults. Bulletin of the Psychonomic Society, 1973, 2, 431-433.

Krueorr, L. E. Familiarity effects in visual information processing. Psychological Bulletin, 1975, 82, 949-974.

KuČera, H., \& Francis, W. N. Computational analysis of present- day American English. Providence, R.I: Brown University Press, 1967.

KuEnNAPAs, T., \& JANson, A.-J. Multidimensional similarity of letters. Perceptual and Motor Skills, 1969, 28, 3-12.

Levine, D. M. Effect of delay times and noise fields on pattern recognition of sequential inputs (Doctoral dissertation, New York University, 1973). Dissertation Abstracts International, 1973, 34, 8968. (University Microfilms No. 73-19396)

Loомrs, J. M. Tactile letter recognition under different modes of stimulus presentation. Perception \& Psychophysics, 1974, 16, 401-408.

Loomis, J. M., \& ApKarian-Stielau, P. A lateral masking effect in tactile and blurred visual letter recognition. Perception \& Psychophysics, 1976, 20, 221-226.

Lysing, H. Secret writing. New York: D. Kemp, 1936.

Maddox, M. E., Burnette, J. T., \& Gutmann, J. C. Font comparisons for $5 \times 7$ dot matrix characters. Human Factors, 1977, 19. 89-93.

MAYzNER, M. S. Studies of visual information processing in man. In R. Solso (Ed.), Information processing and cognition: The Loyola Symposium. Hillsdale, N.J: Erlbaum, 1975.

Mayzner, M. S., \& Tresselt, M. E. Tables of single-letter and digram frequency counts for various word-length and letterposition combinations. Psychonomic Monograph Supplements, $1965,1,13-32$

Mayzner, M. S., Tresselt, M. E., Adler, S., \& Schoenderg, K. M. Correlations between subject generated letter frequencies and observed frequencies in English. Psychonomic Science, $1964,1,295-296$.

Morton, J. The effects of context on the visual duration threshold for words. British Journal of Psychology, 1964, 55, 165-180.

Morton, J. Interaction of information in word recognition. Psychological Review, 1969, 76, 165-178.

NeIsser, U. Cognitive psychology. New York: Appleton-CenturyCrofts, 1967.

PIERce, J. Some sources of artifact in studies of the tachistoscopic perception of words. Journal of Experimental Psychology, 1963, 66, 363-370.

Podgorny, P., \& Garnen, W., R. Reaction time as a measure of inter- and intraobject visual similarity: Letters of the alphabet. Perception \& Psychophysics, 1979, 26, 37-52.

Popp, H. M. Visual discrimination of alphabet letters. Reading Teacher, 1964, 17, 221-226.

Posner, M. I. Abstraction and the process of recognition. In G. H. Bower \& J. T. Spence (Eds.), The psychology of learning and motivation (Vol. 3). New York: Academic Press, 1969.

Posner, M. I., \& Mitchell, R. F. Chronometric analysis of classification. Psychological Review, 1967, 74, 392-409.

Pratt, F. Secret and urgent. Garden City, N.Y: Blue Ribbon Books, 1939.

REINWALD, F. L. Legibility of symbols of the ANDI0400, Mackworth, and Berger type-faces at vertical and horizontal angles of presentation and the construction and test of legibility of a revised type-face (RADC-TR-55-78). Hamilton, N.Y: Department of Psychology, Colgate University, 1955. (NTIS No. AD 075 629)

Robinson, J. S., Brown, L. T., \& Hayes, W. H. Test of effects of past experience on perception. Perceptual and Motor Skills, $1964,18,953-956$.

Roethlein, B. E. The relative legibility of different faces of printing types. American Journal of Psychology, 1912, 23, 1-36.

RoGERs, L. J. Study of the relationship between visual information processing and learning. Unpublished master's thesis, New York University, 1973.

RuDIE, D. D. Recognition of alphabetic inputs as a function of set size and confusability (Doctoral dissertation, New York University, 1974). Dissertation Abstracts International, 1976, 37, 1466B. (University Microfilms No. 76-19609)

SANFord, E. C. The relative legibility of the small letters. American Journal of Psychology, 1887, 1, 402-435. 
Showman, D. J. Studies of display symbol legibility: Part $X$. The relative legibility of Leroy and Lincoln/MITRE alphanumeric symbols (ESD-TR-66-115). Hanscom Field, Mass: USAF Electronic Systems Division, August 1966. (NTIS No. AD 640 170)

Shurtuefr, D. A. Studies of display symbol legibility: XXI. The relative legibility of symbols formed from matrices of dots (ESD-TR-69-432). Hanscom Field, Mass: USAF Electronic Systems Division, February 1970. (NTIS No. AD 702 491) (a)

Shurtlefr, D. A. Studies of display symbol legibility: $X X I I$. The relative legibility of four symbol sets made with a five by seven dot matrix (ESD-TR-70-26). Hanscom Field, Mass: USAF Electronic Systems Division, March 1970. (NTIS No. AD 704 136) (b)

Shurtleff, D., Margetta, M., \& Showman, D. Studies of display symbol legibility: Part IX. The effects of resolution, size, and viewing angle of legibility (ESD-TR-65-411). Hanscom Field, Mass: USAF Electronic Systems Division, May 1966. (NTIS No. AD 633 833)

Sreael, S. Nonparametric statistics. New York: McGraw-Hill, 1956.

Smith, E. E., \& SPoenn, K. T. The perception of printed English: A theoretical perspective. In B. H. Kantowitz (Ed.), Human information processing: Tutorials in performance and cognition. Hillsdale, N.J: Erlbaum, 1974.

SmITH, N. B. Matching ability as a factor in first grade reading. Journal of Educational Psychology, 1928, 19, 560-571.

SNYdER, H. L., \& Maddox, M. E. Information transfer from computer-generated dot-matrix displays (HFL-78-3/ARO-78-1). Blacksburg: Human Factors Laboratory, Virginia Polytechnic
Institute and State University, October 1978. (NTIS No. AD A063 505)

Solso, R. L., \& Kina, J. F. Frequency and versatility of letters in the English language. Behavior Research Methods \& Instrumentation, 1976, 8, 283-286.

Thonndike, E. L., \& Lonos, I. The teacher's word book of 30,000 words. New York: Columbia University, 1944.

TiNKER, M. A. The relative legibility of the letters, the digits, and of certain mathematical signs. Journal of General Psychology, 1928, 1, 472-495.

Townsend, J. T. Theoretical analysis of an alphabetic confusion matrix. Perception \& Psychophysics, 1971, 9, 40-50. (a)

Townsend, J. T. Alphabetic confusion: A test of models for individuals. Perception \& Psychophysics, 1971, 9, 449-454. (b)

Underwood, B. J., \& Schulz, R. W. Meaningfulness and verbal learning. New York: Lippincott, 1960.

UTTAL, W. R. Masking of alphabetic character recognition by dynamic visual noise (DVN). Perception \& Psychophysics, 1969, 6, 121-128.

UTtal, W. R., \& Smith, P. Recognition of alphabetic characters during voluntary eye movements. Perception \& Psychophysics, $1968,3,257-264$

WINER, B. J. Statistical principles in experimental design (2nd ed.). New York: McGraw-Hill, 1971.

Young, C. I., \& Hodge, M. H. Familiarity effects in a samedifferent task with simultaneous and successive presentation. Bulletin of the Psychonomic Society, 1980, 16, 461-464.

(Manuscript received April 10, 1981; revision accepted for publication August 17, 1981.) 